\title{
Reading between the Lines: Contributing Factors that Affect Grade 5 Student Reading Performance as Measured Across South Africa's 11 Languages.
}

\author{
Surette van Staden, Centre for Evaluation and Assessment, University of Pretoria, Surette.vanstaden@up.ac.za \\ Sarah Howie, Centre for Evaluation and Assessment, University of Pretoria, Sarah.howie@up.ac.za
}

This paper reports on the South African results of a study to identify and explain relationships between some major factors associated with successful reading at Grade 5. With 11 official languages, educational policy in South Africa advocates an additive bilingualism model and students in Grade 1 to 3 are taught in their mother tongue. Thereafter, the language of learning and teaching changes to a second language, which in most cases is English. With this complexity of issues, Hierarchical Linear Modeling (HLM) was used to determine the effect of a number of explanatory variables at student- and school level on reading achievement as outcome variable, while controlling for language using the South African PIRLS 2006 data. Utilizing Creemers' Comprehensive Model of Educational Effectiveness (Creemers and Reezigt, 1999) as theoretical point of departure, this paper will focus on the results of an overall South African model with student- and school level variables.

Keywords: secondary analysis, educational policies, reading literacy, PIRLS 2006

\section{Introduction}

This paper forms part of a doctoral project in attempts to understand the factors at student- and school level that affect Grade 5 reading literacy achievement. The PIRLS 2006 project (see Mullis, Martin, Kennedy and Foy (2007) for the PIRLS 2006 International Report) not only serves as a data source and platform which this study was conceptually built upon, but national results of this study also serve as strong evidence for the importance of conducting a study of this nature (see van Staden, 2010).

With 11 official languages, current educational policy in South Africa advocates that students in Grade 1 to 3 are taught in their mother tongue. When these students progress to Grade 4, the language of learning and teaching changes to a second language, which in most cases is English. At this developmental stage, students are also expected to advance from learning to read to a stage where they can use reading in order to learn.

Against this background, this research proposes to identify, illuminate and explain relationships between some major factors associated with successful reading at Grade 5 level in South African primary schools. The attempt to investigate South African students' reading performance (in 11 languages) when given reading tasks in the language of learning and teaching is complex, specifically 
when South Africa's poor reading performance in PIRLS 2006 is taken into account with a Grade 5 average achievement of 302 compared to the international average which is set at 500 . In understanding the reasons for poor reading performance and identifying those factors that can be associated with successful readers, and those factors associated with readers at risk of failure, three systems namely the home (Martin, Mullis and Gonzalez, 2004) and students' background (Leino, Linnakyla and Malin, 2004), the school and the classroom (Howie, 2006, Pasos, 2009) have been shown to be of major influence in reading performance internationally.

International research has revealed that a number of factors at home are important as the process of becoming literate begins long before a child enters a formal educational system. Factors include parents emphasizing reading for meaning, (Fiala and Sheridan, 2003); parents' education, parents' occupation and the number of books at home, students who live with both their parents, resources in the home, and specifically where students have more than 500 books in the home, performance has been proved to be better than those without any books at home (Fuchs and Woessmann, 2004).

Factors related to students themselves include reading motivation and reading related self-perception, students who spend a lot of time reading on their own (Leino et al, 2004); initial experiences with learning to read (Chapman and Tunmer, 2003); and interest and engagement in reading on their own (Linnakyla, Malin \& Taube, 2004). Children master the rudimentary aspects of their native languages during the first years of life. By age three, they should have reached a large and varied lexicon and by age five, their command of a language is relatively sophisticated. This sophistication should increase and progress as the child enters school and learns to read (Ely, 2005). Both English students and English second language students seem to take similar paths of development in specifically prereading skills such as phonological awareness (D’Angiulli, Siegel, \& Maggi, 2004; Gersten and Geva, 2003).

Second language students face two types of difficulties, namely interlingual learning problems caused by mother tongue interference and intralingual learning problems, caused by the structure of the second language (Verhoeven, 1990). Agreement exists that word recognition is a critical part of reading and in learning to recognize words, students use three representational systems, namely: phonemic mapping, recognition of orthographic patterns and direct recognition of words already represented in memory. Children acquiring reading in a second language may experience difficulty with all three of these recognition processes (Verhoeven, 1990).

Furthermore, there is a strong expectation that culture will emerge prominently with regard to many of the factors on these three levels and therefore the decision was made to explore the factors across the five major language groupings (combining the 11 languages into five language groupings). These are discussed in the next section. Factors pertaining to Grade 5 students, through their home 
environment, the classroom and the school, that could impact on reading performance will be identified in this study and used to describe and understand the student profiles within each of the five language groupings (Afrikaans, English, Nguni, Sotho and Tshivenda) in South Africa. It is the first time that South Africa has data on reading literacy for all languages with international comparable data that can be analysed on a number of levels.

The following sections of this paper will focus on the language profile of South Africa, followed by a description of the conceptualization and methodology used for the purposes of this study. The paper concludes with a discussion of results and conclusions.

\section{The Language Profile of South Africa}

The language profile of South Africa paints a very complex picture. During the Apartheid era South Africa had two official languages, namely English and Afrikaans. The end of the Apartheid era brought about a new constitution that gave official status to 11 local languages. Table 1 provides an indication (as taken from Mesthrie, 2002) from the 1996 Census, of numbers and percentages of people speaking each of the official languages in South Africa:

A distinction needs to be made, amongst the complexity of languages in South Africa, between 'mother-tongue', 'language of learning' and 'language of the test'. While South African children start their learning at school from Grade 1 to 3 in their home language (mother tongue), many schools are faced with teaching students in these grades in a language of learning that is different from what the children speak at home. For the majority of students entering Grade 4, the language of learning changes (again), resulting in more than $80 \%$ of students being taught in a second language (mostly English, a language spoken by less than $10 \%$ of the population). For Grade 1 to 3 students, 'home language' does not necessarily coincide with 'language of learning' (or the 'language of the test'). For example, a Xitsonga-speaking student may attend a school that teaches in isiZulu, only to switch to English as language of learning by Grade 4. For the purposes of data analysis in this study, language groupings will therefore be defined by means of 'language of learning' (in Grades 1 to 3), which was also the 'language of the test' in PIRLS 2006 since the term 'home language' is not an accurate indication of whether or not a student did in fact receive instruction in his or her home language.

\section{Conceptualization of the study}

For the purposes of this study, Creemers' Comprehensive Model of Educational Effectiveness (Creemers and Reezigt, 1999) for schools was used as point of departure, as this model most closely bears relevance to already existing reading achievement literature. Creemers' work provides an extensive analytical model in this study's attempt to evaluate achievement across language groups. 
Creemers' model focuses on the explanation of student outcomes by alterable educational factors by discerning contrasting but connected levels of structure for effectiveness in education (Creemers and Reezigt, 1999). Higher levels provide condition for lower levels and educational outcomes are induced by the combined effects of levels. The nested structure of the PIRLS 2006 South African data and the hierarchical nature of the Creemers model mean that the current study and the model have many variables in common. It is recognized that, since the conceptualization of this $\mathrm{PhD}$ study, the Dynamic Model of Educational Effectiveness (Creemers \& Kyriakides, 2008) has concurrently been developed. However, for the purposes of the current study, a decision was made to make adaptations to the original Comprehensive Model of Educational Effectiveness as proposed by Creemers, rather than the newly revised Dynamic Model. The Dynamic Model makes provision for investigation across time with multiple times for data collection, but for the purposes of this study, the available cross-sectional data was collected at one particular time with no follow-up or repeat measures. The Comprehensive Model of Educational Effectiveness is well established and has been critically reviewed for its validity in studies of educational effectiveness. Creemers (in print) states that although a dynamic model of educational effectiveness is proposed, the original model could provide a starting point for developing a dynamic model of educational effectiveness research.

Three levels of the system are influential in analyzing reading achievement, namely the school, the classroom, and the home and students' background in order to identify those factors that can be associated with successful readers and those factors associated with readers at risk of failure. Creemers' Comprehensive Model of Educational Effectiveness for schools (Creemers and Reezigt, 1999; Kyriakides, Campbell \& Gagatsis, 2000; Kyriakides and Creemers, 2006) is used as point of departure for this research, providing an extensive analytical model to analyse achievement across the five language groupings.

Creemers' model is built around the characteristics of time, opportunity used and quality at both student- and school levels. Time and opportunity are discerned at the classroom and school level, in this way making the distinction between actually used time and available opportunity. Bos (2002) explains that Creemers therefore emphasized the availability of time and opportunity at the classroom level, while at the student level referring to actual time used and opportunity to learn.

For the purposes of this study, Creemers' Comprehensive Model of Educational Effectiveness was adapted to that of a model of reading effectiveness. In terms of components of quality, time and opportunity for each of the four levels, the following adaptations guided the study based on components and factors assessed by PIRLS 2006. Table 2 illustrates Creemers' levels in terms of context, school, classroom and student along with components of quality, time and opportunity. These components were populated with the PIRLS 2006 variables, as illustrated by the right hand column of Table 2. The PIRLS 2006 variables are derived from factors measured by the PIRLS 2006 school, 
teacher, parent and student contextual questionnaires.

\section{Research questions}

In South Africa, two grades (Grades 4 and 5) were tested for PIRLS 2006. This study is a secondary analysis of the PIRLS 2006 South African Grade 5 data. The main research question that guided the project was:

What are the factors that could be associated with Grade 5 student performance in reading literacy in an overall South African model? ${ }^{1}$

Factors emanating from contextual questionnaires of Grade 5 students, their home environment, their schools and classrooms were analyzed in relation to students' achievement scores on the PIRLS 2006 reading tests. The main research question comprises the following sub-questions:

1. What factors related to the students' background (for example motivation to read, language skills and home environment) affect performance in reading literacy in the overall South African model?

2. To what extent do the school and classroom environments affect reading literacy performance in the overall South African model?

3. How do these relationships between factors differ or remain constant across the 11 official languages in South Africa at least in light of the five language groupings?

\section{Methodology}

For the purposes of answering these questions, Hierarchical Linear Modeling (HLM), also known as Multi Level Modeling (Snijders and Bosker, 2002), was used to determine the effect of a number of explanatory variables at student- and school-level on reading achievement as outcome variable, while controlling for language. The aim of these analyses was to establish the relationships between one or more explanatory ${ }^{2}$ variables (in this case obtained from items in the contextual questionnaires on student and school level) and the outcome variables (reading achievement scores for the different language groups), taking into account that the nested structure of the data means that students are in

\footnotetext{
${ }^{1}$ This paper only reports on main effects for the overall South African model. For a detailed description of the interaction effects per language grouping, the reader is referred to Van Staden, S. (2010), Reading between the lines : contributing factors that affect Grade 5 learner reading performance, $\mathrm{PhD}$ thesis, University of Pretoria, Pretoria.

${ }^{2}$ The term 'explanatory' explicitly suggests the explanatory role with respect to the independent variable.
} 
classes, and classes are in schools. The analysis of the PIRLS 2006 achievement and questionnaire data followed a confirmatory, and not exploratory, approach. Instead of using all variables available to the researcher from the different questionnaires, only a selection of variables that were expected to be related to reading literacy achievement (and in correspondence with the conceptual framework) was used for analysis purposes. In this way, the study was not guided by the available data alone, but rather by existing research into what is known about the factors that are likely to influence student reading achievement.

For the purposes of building multilevel models more effectively, it was decided not to analyze data individually for each of the 11 official languages. It has to be kept in mind that 11 official languages imply that analyses would have had to be repeated and replicated 11 times over, with a chance that, due to small sample size, the languages spoken by less than $5 \%$ of the South African population (namely isiNdebele, Siswati, Tshivenda and Xitsonga) would be excluded from the analyses. Among the 11 languages linguistic and grammatical charactertistics are shared, therefore the PIRLS 2006 data was theoretically reduced from 11 language categories and recoded into five language groupings, namely Afrikaans, English and Tshivenda as lone-standing language groupings, followed by the Nguni languages (consisting of isiNdebele, isiXhosa, isiZulu, Siswati and Xitsonga, all of which share linguistic and grammatical similarities), and the Sotho languages (consisting of Sepedi, Sesotho and Setswana, also languages which share linguistic and grammatical similarities). Van Staden (2010) illustrates through the use of ANOVA that the five language groupings could be considered homogenous. Average achievement scores (keeping in mind that the international average is set at 500) on the PIRLS 2006 reading assessment for these language groupings and their variance are provided in Table 3:

The South African sample for PIRLS 2006 consisted of 441 schools, all of which offer schooling at least at Grade 4 level. From an initial 15182 schools the South African sample was proportionally selected, first by province and then by language of teaching within province to arrive at this intended sample of 441 schools. Information on seven of the selected schools was absent to such an extent that these schools could not be traced. Thus, the PIRLS 2006 study resulted in the collection of achievement- and contextual data from a realized sample of 434 schools comprising 14657 Grade 5 students from intact classrooms (see Howie, Venter, van Staden, Zimmerman, Long, Scherman \& Archer, 2009).

\section{Results}

In this section, the results of the overall South African model will be discussed in light of each of the research questions, keeping in mind that for the purposes of this study, a two level model was used, with learner-level variables nested within school-level variables. School and classroom-level 
variables are grouped together in one level, since variables at these levels cannot be separated from one another. The PIRLS 2006 sample was drawn so that one intact classroom was chosen from each selected school, thereby making classrooms inextricably part of the school. The concept of causality is used with great care in this study, since causal conclusions cannot be drawn from non-experimental data. Instead, this study seeks to generate associations and directions of relationships between explanatory and outcome variables.

Results of the overall South African model are preceded by presenting a null (or empty) model. The null model (as also used by Shalabi, 2002 and described by Luke, 2004; Hox, 2002 and Heck \& Thomas, 2000) has no explanatory variables and should provide the basic partition of the variability in the data between the learner- and school-level in the ensuing models. The null model can therefore be expressed as:

$\beta 0=\gamma 00+U 0$

$\beta 0$ is the level 1 intercept, $\gamma 00$ is the mean value of the level- 1 outcome across all level- 2 units, and $U O$ is the deviation from the grand mean. Table 4 (below) shows the results of the overall null model:

Table 4 (above) indicates the existence of significant differences between South African schools in reading literacy achievement. The between school variance for the null model is $42 \%^{3}$ of the total variance. Based on the partition of this variability, an overall South African model, populated with explanatory variables, can be presented.

Table 5 provides results for the overall South African model (see van Staden, 2010, for a detailed discussion on the selection of variables for analysis purposes). The intercept indicated provides South African Grade 5 readers with an average English reading achievement score of $524.33\left(\mathrm{SE}=22.53^{4}\right)$.

\section{What factors related to the students' background (for example motivation to read, language skills and home environment) affect performance in reading literacy for each language group?}

\footnotetext{
${ }^{3}$ The percentage of explained variance for the null model was obtained as follows: $12,693.7-7,290.2 / 12,693.70$ $=0.42$ or $42 \%$ variance. This procedure was followed in computing variance for all models discussed in this chapter.
}

${ }^{4}$ All SE's are provided in parentheses. All other coefficients provided in Table 4 are interpreted relative to the intercept. Also note that every one point increase or decrease in coefficients (or explanatory variables) is relative to the intercept (or dependent variable, which refers to average reading achievement for the English language grouping). 
At student level, time spent on reading, opportunities used for reading by student and parent, as well as student- and parent social background were included in the model. Aspects at student-level only included student age and sex, since these biographical variables have repeatedly been proven to be significant predictors of reading achievement (Howie, 2002; Howie, 2003; Howie, 2006; Pasos, 2009).

Factors at the student-level were all significant contributors to average reading achievement scores, except for reading time created by parents. For each year increase in student age while remaining in Grade 5, reading achievement decreases with 8.76 (2.00) points. Sex significantly decreases reading achievement in favour of girls by 27.50 (2.80) points ${ }^{5}$. Where students do not spend time on reading, reading achievement scores decrease by 9.55 (1.42) points. Where students use opportunities to read, reading achievement increases by 10.50 (1.33) points. The different effects between these two factors on reading achievement may point to possible interaction effects, since these two factors may point to the same behaviour exhibited by students and may only be conceptually different.

Where parents fail to create opportunities for their children to read, average reading achievement decreases by 8.32 (1.27) points. Of interest in Table 4 is to note that parents' reported time spent on reading with their children does not influence average reading achievement scores significantly. This result should be interpreted with caution, since the statistical non-significance of time spent on reading does not necessarily mean that time has no influence. This factor should be interpreted relative to the statistical significance of opportunities created by the parent to read with the child. In practice, the difference between parents providing time for reading with their children and creating opportunities for reading may constitute the same behaviour. The difference in providing opportunities to read and time spent reading may therefore only be a conceptual difference that was used for the purposes of this study, yet resulting in the same behaviour.

Lastly, the overall South African model indicates that parent and student social background, as measured by possessions in the home and parents' level of educational qualifications, significantly influence average reading achievement scores. In higher socio-economic households, average reading scores were on average higher by 6.30 (1.51) points compared to those households with lower socioeconomic status, fewer possessions and lower educational qualifications for parents. These results are consistent with international research findings which have repeatedly found socio economic status to be the single biggest predictor of student achievement in school in other learning areas too. While socio economic status has importance for other learning areas, this study presents strong evidence for its effect on reading achievement in particular.

\footnotetext{
${ }^{5}$ All variables were coded from low to high. In the case of sex, girls are identified by 1 , boys by 2 , therefore the decrease in reading achievement scores would pertain to boys' achievement.
} 
Table 6 indicates the variance components for the overall model:

The variance component of the overall model when language groupings are deleted from the model indicates that the variance between schools $(7,671.91)$ is larger than the variance within schools $(6,822.94)$. This pattern is typical of that found in developing countries and contrary to the pattern of variance in developed countries where variance within schools is larger than the variance between schools. The implication of a larger variance between schools means that interventions can more easily be implemented, since the intervention can be tailored at school level to meet the needs of the school. With a larger variance within schools, planning and implementing interventions become more complicated, since differences at classroom level are much more varied and one-size-fits-all interventions often do not address the variations encountered within the class.

However, with the inclusion of language groupings in the model, the variance component changes significantly to a pattern where variance within schools is larger than between $(6,687.03$ within schools as opposed to 2,512.04 between schools). This difference in variance components for the overall model suggests that the addition of language groupings to the model accounts for $36 \%$ of variance in the overall South African model.

\section{To what extent do the school and classroom environments affect reading literacy performance for each language group?}

At school-level, school and classroom variables of educational quality, time spent on reading activities and opportunities created for reading were included in the model. Educational quality refers specifically to those activities undertaken by teachers in the classroom to teach, promote and engage students in reading. Time spent on reading refers to the measurable aspects of actual time devoted by the teacher and the school on reading activities. Opportunities created by teachers at classroom level and schools are those opportunities afforded to Grade 5 students to engage in reading at school, variables related to the existence of informal initiatives, the use of materials in school and the involvement of parents in school activities.

Table 5 indicates that only one of the teacher level variables were significant in the overall model. The only significant factor at school level was that of reading opportunity created by the teacher. Where teachers fail to create such opportunities for students, average reading achievement appears to decrease by $14.12(5.44)$ points.

It will be noted that Table 5 also comprises a variable for school socio economic status. This variable was created to convey the social background of the school by averaging indices of resources across 
the number of children in the school. The interpretation of the model now allows for explanations of teacher- and school-level time spent on reading, opportunities created by the teacher and school for reading and the quality of teachers that may vary across the districts within socio economic contexts that were accounted for in the model. The overall model therefore shows that, given teacher and school time spent on reading, opportunities created for reading and teacher quality, school socio economic status still leads to an increase of 69.10 (5.21) points in average reading achievement. The effect of school socio economic status of students in this model is therefore consistent with other research, which identifies socio economic status as the major predictor of differential reading achievement.

\section{How do these relationships between factors differ or remain constant across the 11 official languages in South Africa at least in light of the five language groupings?}

Table 5 indicates that Afrikaans student achievement decreased by 10.93 points (11.17) relative to English, which served as the control language for this model. This decrease was, however not statistically significant. Of significance was the decrease in all the African language grouping average reading achievement scores relative to the control language - a significant decrease by 70.90 points (12.75) for the Nguni group, a significant 68.00 point (11.80) decrease for the Sotho grouping, as well as a significant 73.51 point (15.80) decrease for Tshivenda. These results indicate that, relative to English, the Afrikaans language grouping was the only one of the five tested South African language groupings whose average reading achievement score did not differ significantly from English, the control language for which the intercept was 524.33 (22.53).

\section{Discussion and conclusion}

The essence of the research questions of this study sought to investigate the factors that are related to the students' background that affect performance in reading literacy, the extent to which the school and classroom environments affect reading literacy performance, and the manner in which these relationships between factors differ or remain constant across the 11 official languages in South Africa at least in light of the five language groupings. For the purposes of answering these questions, Hierarchical Linear Modeling (HLM) was used to determine the effect of a number of explanatory variables at student- and school level on reading achievement as outcome variable, while controlling for language.

The model results of this study pointed to the fact that many statistically significant variables can be found at the student level. Age was an important predictor of reading achievement, with the implication that reading achievement shows downward patterns as the child grows older while 
remaining at Grade 5 level. This evidence clearly suggests that a suitable approach to underachievement is the early diagnosis and targeted support of students with difficulties. This, however, is easier said than done, since many teachers in South African classrooms are faced with large classes and little experience in diagnostic testing. Anecdotal evidence points to some teachers' dilemmas where, even when they are aware of students with difficulties in their classrooms, they are not knowledgeable in taking appropriate steps in providing the correct support or additional assistance to target the problem.

The model results for this study also showed that sex was statistically significant in predicting student achievement, with boys perpetually achieving lower reading achievement scores than girls. In line with international patterns of reading achievement between boys and girls, national interventions could therefore be aimed and targeted at boys - if only to serve as an avenue to get boys interested in reading whatsoever.

School-level results that emanated from this study pointed to the fact that very few statistically significant factors could be found at classroom- and school-level for each of the models that were built in this study. No school-level factors, apart from teacher time spent on reading was found to be of statistical significance. The results of this study therefore confirm patterns found in developing contexts and the results of one other study that was done for mathematics achievement in South Africa (Howie, 2002).

The importance of these factors at classroom- and school level, should however, not be diminished. A lack of statistical significance should not be regarded as lack of importance of the factor's effect on reading achievement in totality. Instead, statistically significant effects could be hidden from the current data source, but yet still represent important effects on reading achievement as mirrored by literature on the topic and what is known about that which works in terms of classroom practice.

Creemers' framework was used as it supported preliminary ideas about reading achievement most closely. However, although the presupposed model was apparently adequate for the overall, Afrikaans and English models (see van Staden, 2010), the framework did not fit patterns found for the African languages, and may therefore suggest further changes to the framework to suit the South African landscape more adequately. Creemers' Model of Educational Effectiveness as conceptual framework in this study begs the following question: To what extent does the presupposed model capture the PIRLS 2006 data adequately? It can be argued that it was never the intention for the PIRLS 2006 data to fully capture Creemers' Model, since the model was not used here to broaden an understanding of school effectiveness. Nonetheless, it was used as theoretical point of departure for this study without the intent to be fully captured by the PIRLS 2006 data. 
Reflections on the conceptual framework used in this study and the study of PIRLS 2006 data to adequately mimic the components as specified by Creemers, invite another question: How should the model change to suit the South African landscape more adequately? Perhaps modifications should be explored rather than confirmed, since use of the South African PIRLS 2006 data source to capture the essence of Creemers' components often resulted in the elimination of or adaptation to factors.

Another model aspect where evidence may have been suppressed in the data and not adequately reflect the conceptual framework, was that the school and teacher was inseparable given the sampling of one class representing the school. The inseparability of the school and teacher could be mediated with the inclusion of more teacher or classroom data and invites the following question for consideration in future research: Could more than one classroom per school warrant changes of design, thereby improving the explanatory power of this model? For example, could data in future be selected from two or more classrooms per school, with fewer sampled schools, and if so, could the choice of such schools for a second classroom be random choices of schools that have been already stratified by some salient feature (e.g. school variability)?

In conclusion, evidence presented by this study confirms that Grade 5 students in South African primary schools who participated in PIRLS 2006 were not able to achieve satisfactory levels of reading competence. The gravity of this finding is exacerbated by the fact that these students were tested in the language in which they had been receiving instruction during the Foundation Phase of schooling.

The cultivation of a passion for reading, a culture of reading in South African households, classrooms and schools and the continual monitoring of reading achievement remain imperatives for the South African schooling system in years to come. The importance of a reading literate country is emphasized in the introduction of the PIRLS 2006 International Report:

"In today's information society, the ability to read is essential for maximizing success in the endeavours of daily life, continuing intellectual growth, and realizing personal potential. Similarly, a literate citizen is vital to a nation's social growth and economic prosperity." (Martin et al, 2007:15).

The ultimate cost of an illiterate population for whom reading is of non-significance would ultimately culminate in dire life-long economic and social consequences, both for the individual and communities. 


\section{References}

Bos, K. Tj. (2002). Benefits and limitations of large-scale international comparative achievement studies: The case of IEA's TIMSS Study. Enschede: PrintPartners Ipskamp.

Chapman, J.W. and Tunmer, W.E. (2003). Reading difficulties, reading related self-perceptions and strategies for overcoming negative self-beliefs. Reading and Writing Quarterly, 19, 5-24.

Creemers, B.P.M. (in print). Chapter 4: Empirical testing of the Comprehensive Model of Educational Effectiveness: Review of Research.

Creemers, B.P.M and Reezigt, G.J. (1999). The concept of vision in educational effectiveness theory and research. Learning Environments Research, 2, 107-135.

Creemers, B.P.M \& Kyriakides, L. (2008). The dynamics of Educational effectiveness: A contribution to policy, practice and theory in contemporary schools. Abingdon: Routledge.

D’Angiulli, A., Siegel, L.S. \& Maggi, S. (2004). Literacy instruction, SES and word-reading achievement in English-language students and children with English as a first language: A longitudinal study. Learning Disabilities Research and Practice, 19(4), 202-213.

Ely, R. (2005). The Development of Language. Boston: Allyn and Bacon.

Fiala, C. L. and Sheridan, S.M. (2003). Parent involvement and reading: Using curriculum-based measurement to assess the effects of paired reading. Psychology in the Schools, 40(6), 613-626.

Fuchs, T. and Woessmann, L. (2004). What accounts for international differences in student performance? A re-examination using PISA data. (CESifo Working Paper No. 1235). Retrieved from http://www.ifo.de/portal/pls/portal/docs/1/1189152.PDF

Gersten, R. and Geva, E. (2003). Teaching reading to early language learners. Educational Leadership, 60(7), 44-49.

Heck, R.H. \& Thomas, S.L. (2000). An Introduction to Multilevel Modeling Techniques. Mahwah, NJ: Lawrence Erlbaum Associates.

Howie, S.J. (2002). English language proficiency and contextual factors influencing Mathematics achievement of secondary school pupils in South Africa. Enschede: Printpartners Ipskamp.

Howie, S.J. (2003). Language and other background factors affecting secondary pupils' achievement in Mathematics in South Africa. African Journal of Research in Mathematics, Science and Technology Education, 7, 1-20.

Howie, S.J. (2006). Multi-level factors affecting the achievement of South African pupils in Mathematics. In: Howie, S.J. \& Plomp, T. (eds). Contexts of Learning and Science. London: RoutledgFalmer.

Howie, S.J., Venter, E., van Staden, S., Zimmerman, L., Long, C., Scherman, V. and Archer, E. (2009). PIRLS 2006 Summary Report: South African children's reading literacy achievement. Pretoria: Centre or Evaluation and Assessment.

Hox, J.J. (2002). Multilevel analysis: Techniques and Applications. Mahwah, NJ: Lawrence Erlbaum Associates. 
Kyriakides, L., Campbell, R.J. \& Gagatsis, A. (2000). The significance of the classroom effect in primary schools: An application of Creemers' Comprehensive Model of Educational Effectiveness. School Effectiveness and School Improvement, 11(4), 501-529.

Kyriakides, L. and Creemers, B.P.M. (2006, April). Testing the dynamic model of educational effectiveness: Teacher effects on cognitive and affective outcomes. Paper presented at the $87^{\text {th }}$ annual meeting of the American Educational Research Association, San Francisco, USA.

Leino, K., Linnakyla, P. \& Malin, A. (2004). Finnish students' multiliteracy profiles. Scandinavian Journal of Educational Research, 48(3), 251-270.

Linnakyla, P., Malin, A. \& Taube, K. (2004). Factors behind low reading literacy achievement. Scandinavian Journal of Educational Research, 48(3). 231-249.

Luke, D.A. (2004). Multilevel Modeling. Sage Publications: Thousand Oaks.

Martin, M.O., Mullis, V.S. \& Gonzalez, E. (2004, May). Home environments fostering children's reading literacy: Results from the PIRLS 2001 study of reading literacy achievement in primary schools in 35 countries. Paper presented at the $1^{\text {st }}$ IEA International Research Conference, Lefkosia, Cyprus.

Mesthrie, R. (ed) (2002). Language in South Africa. Cambridge: Cambridge University Press. Martin, M.O., Mullis, I.V.S. \& Kennedy, A.M. (Eds.). (2007). PIRLS 2006 Technical Report. Chestnut Hill: Boston College.

Mullis, I.V.S., Martin, M.O., Kennedy, A.M. \& Foy, P. (2007). PIRLS 2006 International Report: IEA's Study of Reading Literacy Achievement in Primary Schools. Chestnut Hill: Boston College. Pasos, A.F.J. (2009). A Comparative Analysis of Teacher Competence and its Effect on Pupil Performance in Upper Primary Schools in Mozambique and other SACMEQ Countries. University of Pretoria: PhD.

Shalabi, F. (2002). Effective Schooling in the West Bank. University of Twente, Enschede: Twente University Press.

Snijders, T. and Bosker, R. (1999). Multi level analysis: An introduction to basic and advanced multi level modeling. London: Sage Publications.

Van Staden, S. (2010). Reading between the lines: Contributing factors that affect Grade 5 learner reading performance. Unpublished doctoral dissertation: University of Pretoria.

Verhoeven, L.T. (1990). Acquisition of reading in a second language. Reading Research Quarterly, 25(2), 90-114. 
Table 1: Percentage of the population speaking the 11 official Languages in South Africa, percentage of the PIRLS sample and mean score for reading literacy

\begin{tabular}{|l|r|r|r|r|}
\hline $\begin{array}{c}\text { Languages per } \\
\text { group }\end{array}$ & $\begin{array}{c}\text { Percentage } \\
\text { of the } \\
\text { population }\end{array}$ & $\begin{array}{c}\text { Percentage of } \\
\text { the PIRLS } \\
\text { sample }\end{array}$ & \multicolumn{2}{|c|}{$\begin{array}{c}\text { PIRLS 2006 } \\
\text { Mean score }\end{array}$} \\
\hline Nguni & 1.5 & .66 & 176.8 & 9.0 \\
\hline isiNdebele & 2.5 & 2.4 & 211.6 & 6.5 \\
\hline SiSwati & 17.9 & 14.6 & 189.9 & 6.5 \\
\hline isiXhosa & 22.9 & 26.5 & 229.0 & 7.9 \\
\hline isiZulu & 4.4 & 2.4 & 221.7 & \\
\hline Xitsonga & & & & \\
\hline Sotho & 9.2 & 8.7 & 203.9 & 8.6 \\
\hline Sepedi & 7.7 & 3.9 & 214.2 & 5.6 \\
\hline Sesotho & 8.2 & 7.2 & 255.0 & 6.3 \\
\hline Setswana & & & & \\
\hline Other & 2.2 & 2.5 & 214.1 & 10.4 \\
\hline Tshivenda & 14.4 & 8.7 & 351.7 & 12.0 \\
\hline Afrikaans & 8.6 & 22.1 & 346.8 & 17.5 \\
\hline English & & & & \\
\hline
\end{tabular}


Table 2: Factors Related of Reading Effectiveness (Source: van Staden, 2010)

\begin{tabular}{|c|c|c|}
\hline Levels & $\begin{array}{l}\text { Components of Quality, } \\
\text { Time and Opportunity }\end{array}$ & PIRLS 2006 Variables \\
\hline Context & $\begin{array}{l}\text { Quality: } \\
\text { Time: } \\
\text { Opportunity: }\end{array}$ & $\begin{array}{l}\text { Demographics and resources } \\
\text { Teacher training and preparation } \\
\text { Curriculum characteristics and policies } \\
\text { Governance and organization of educational system }\end{array}$ \\
\hline School & $\begin{array}{l}\text { Quality (educational): } \\
\text { Quality: (organizational) } \\
\text { Time: } \\
\text { Opportunity: }\end{array}$ & $\begin{array}{l}\text { School environment and resources } \\
\text { Instructional activities and strategies } \\
\text { Governance and organization of educational system } \\
\text { Teacher training and preparation } \\
\text { Home-school connection } \\
\text { Curriculum characteristics and policies }\end{array}$ \\
\hline Classroom & $\begin{array}{l}\text { Quality: } \\
\text { Time: } \\
\text { Opportunity: }\end{array}$ & $\begin{array}{l}\text { Demographics and resources } \\
\text { School environment and resources } \\
\text { Instructional materials and technology } \\
\text { Teacher training and preparation } \\
\text { Classroom environment and structure } \\
\text { Instructional strategies and activities } \\
\text { Home-school connection }\end{array}$ \\
\hline Student & $\begin{array}{l}\text { Quality: } \\
\text { Opportunities used: } \\
\text { Motivation: } \\
\text { Social background: } \\
\text { Basic skills/Higher order } \\
\text { skills: }\end{array}$ & $\begin{array}{l}\text { Students' out-of-school activities } \\
\text { Home-school connection } \\
\text { Activities fostering reading literacy } \\
\text { Demographics and resources } \\
\text { School environment and resources } \\
\text { Home resources } \\
\text { Language in the home }\end{array}$ \\
\hline
\end{tabular}

(Adapted from Creemers' Comprehensive Model of Educational Effectiveness) 
Table 3: Average Grade 5 Achievement Score Nationally and per Language Grouping with Weighted Variance

\begin{tabular}{|l|r|r|r|r|}
\hline \multicolumn{1}{|c|}{$\begin{array}{c}\text { Language } \\
\text { Grouping }\end{array}$} & N & \multicolumn{1}{c|}{$\begin{array}{c}\text { Average } \\
\text { Achievement Score }\end{array}$} & $\begin{array}{c}\text { Weighted } \\
\text { Variance (Total } \\
\text { Student } \\
\text { Weight) }\end{array}$ \\
\hline $\begin{array}{l}\text { South African } \\
\text { National Results }\end{array}$ & 14,657 & 302.0 & 5.6 & \\
\hline Afrikaans & 1,678 & 415.7 & 12.0 & $17,027.5$ \\
\hline English & 2,793 & 398.0 & 17.1 & $24,012.1$ \\
\hline Nguni & 6,039 & 243.3 & 4.4 & $9,386.4$ \\
\hline Sotho & 3,363 & 267.1 & 5.2 & $9,021.1$ \\
\hline Tshivenda & 784 & 262.1 & 15.0 & $9,291.6$ \\
\hline
\end{tabular}

Table 4: Estimation of the Variance Components for the Overall Null Model

$\begin{array}{lll}\text { Variables } & \text { Estimate } & \text { SE } \\ \text { Grand mean } & 307.3 & 8.0 \\ \text { Variance components: } & & \\ \text { School level } & 12,693.7 & \\ \text { Learner level } & 7,290.2 & \end{array}$


Table 5: Overall Model Results for the PIRLS 2006 South African Data

\begin{tabular}{|c|c|c|c|}
\hline Fixed Effect & Coefficient & Standard Error & P-Value \\
\hline Intercept & 524.33 & 22.53 & $0.00^{1}$ \\
\hline \multicolumn{4}{|l|}{ School and Classroom Level } \\
\hline School socio economic status & 69.10 & 5.21 & 0.00 \\
\hline Afrikaans & -10.93 & 11.17 & 0.32 \\
\hline Nguni & -70.90 & 12.75 & 0.00 \\
\hline Sotho & -68.00 & 11.80 & 0.00 \\
\hline Tshivenda & -73.51 & 15.80 & 0.00 \\
\hline Teacher quality & 11.87 & 5.66 & 0.03 \\
\hline $\begin{array}{l}\text { Teacher time spent on reading in } \\
\text { class }\end{array}$ & 1.09 & 5.34 & 0.83 \\
\hline $\begin{array}{l}\text { Reading opportunity created by } \\
\text { teacher }\end{array}$ & -14.12 & 5.44 & 0.01 \\
\hline School educational quality & 6.80 & 3.65 & 0.06 \\
\hline School time spent reading & 8.90 & 4.03 & 0.02 \\
\hline $\begin{array}{l}\text { Reading opportunity created by } \\
\text { school }\end{array}$ & 1.18 & 3.30 & 0.71 \\
\hline \multicolumn{4}{|l|}{ Student Level } \\
\hline Student age & -8.76 & 2.00 & 0.00 \\
\hline Student sex & -27.50 & 2.80 & 0.00 \\
\hline Student time spent reading & -9.55 & 1.42 & 0.00 \\
\hline $\begin{array}{l}\text { Reading opportunity used by } \\
\text { student }\end{array}$ & 10.50 & 1.33 & 0.00 \\
\hline Reading time created by parent & 2.00 & 1.24 & 0.11 \\
\hline $\begin{array}{l}\text { Reading opportunity created by } \\
\text { parent }\end{array}$ & -8.32 & 1.27 & 0.00 \\
\hline $\begin{array}{l}\text { Student and parent social } \\
\text { background }\end{array}$ & 6.30 & 1.51 & 0.00 \\
\hline
\end{tabular}

Table 6: Variance Components for the Overall Model

\begin{tabular}{|l|l|}
\hline Variance between schools & $7,671.91$ \\
\hline Variance within schools & $6,822.94$ \\
\hline
\end{tabular}

\footnotetext{
${ }^{1}$ Significance is reported where $\mathrm{p}=<0.01$.
} 